https://helda.helsinki.fi

Occupational variation in the risk of female breast cancer in the Nordic countries

\title{
Katuwal, Sushmita
}

2018-11

Katuwal , S , Martinsen , J I Kjaerheim , K, Sparen , P , Tryggvadottir , L , Lynge , E , Weiderpass , E \& Pukkala , E 2018 , ' Occupational variation in the risk of female breast cancer in the Nordic countries ' , Cancer Causes \& Control , vol. 29 , no. 11 , pp. 1027-1038 . https://doi.org/10.1007/s10552-018-1076-2

http://hdl.handle.net/10138/273454

https://doi.org/10.1007/s10552-018-1076-2

publishedVersion

Downloaded from Helda, University of Helsinki institutional repository.

This is an electronic reprint of the original article.

This reprint may differ from the original in pagination and typographic detail.

Please cite the original version. 


\title{
Occupational variation in the risk of female breast cancer in the Nordic countries
}

\author{
Sushmita Katuwal ${ }^{1}$ Jan Ivar Martinsen ${ }^{2} \cdot$ Kristina Kjaerheim $^{2} \cdot$ Pär Sparen $^{6} \cdot$ Laufey Tryggvadottir $^{7,8}$. \\ Elsebeth Lynge $^{9} \cdot$ Elisabete Weiderpass $^{2,3,4,5,6} \cdot$ Eero Pukkala ${ }^{1,10}$
}

Received: 1 March 2018 / Accepted: 23 August 2018 / Published online: 27 August 2018

(c) Springer Nature Switzerland AG 2018

\begin{abstract}
Objective This study aimed to determine occupational variations in the incidence of breast cancer in the population-based cohort of Nordic Occupational Cancer Study (NOCCA).

Methods The study included long-term follow-up data from almost 7.5 million Nordic women. Participants were assigned to one of the 54 occupational categories based on census records at the ages of 30-64 years. Sixty-two thousand cases of breast cancer were identified through record linkages between nationwide cancer registries in Finland, Sweden, Norway, Denmark, and Iceland, followed up between 1961 and 2005. Country-specific standardized incidence ratios (SIRs) with 95\% confidence intervals were estimated.

Results Overall, the highest risk elevations were seen among military personnel (SIR 1.58, 95\% CI 1.03-2.32), dentists (SIR 1.43, 95\% CI 1.31-1.56), and physicians (SIR 1.35, 95\% CI 1.26-1.46). The lowest risks were observed among gardeners (SIR 0.76, 95\% CI 0.74-0.78), farmers (SIR 0.80, 95\% CI 0.78-0.82), and woodworkers (SIR 0.75, 95\% CI 0.70-0.81). Welders, tobacco workers, and painters had higher SIRs for breast cancer diagnosed at age $<50$. A reduced risk was observed among forestry workers, welders, and fishery workers for breast cancers diagnosed both before and after age 50. The SIRs for breast cancer did not vary substantially by histology. A significantly increased risk of breast cancer was observed among laboratory workers in the latest calendar period (1991-2005) compared with earlier periods (1976-1990 and 1961-1975). Occupations such as farming, forestry, driving, and gardening had low SIRs during all periods.

Conclusions The study suggests that the risk of breast cancer varies by occupation. Heterogeneity is also observed in some occupational categories according to age (before or after 50), histology, and calendar period.
\end{abstract}

Keywords Breast cancer $\cdot$ Nordic $\cdot$ Occupational exposure $\cdot$ Risk factors

Sushmita Katuwal

sushmita.katuwal@staff.uta.fi

1 Faculty of Social Sciences, University of Tampere, Tampere, Finland

2 Department of Research, Cancer Registry of Norway, Institute of Population-Based Cancer Research, Oslo, Norway

3 Department of Community Medicine, Faculty of Health Sciences, University of Troms $\varnothing$, Troms $\varnothing$, Norway

4 Genetic Epidemiology Group, Folkhälsan Research Centre, Helsinki, Finland
5 Faculty of Medicine, Helsinki University, Helsinki, Finland

6 Department of Medical Epidemiology and Biostatistics, Karolinska Institutet, Stockholm, Sweden

7 Icelandic Cancer Registry, Reykjavik, Iceland

8 Faculty of Medicine, University of Iceland, Reykjavik, Iceland

$9 \quad$ Centre for Epidemiology and Screening, Institute of Public Health, University of Copenhagen, Copenhagen, Denmark

10 Finnish Cancer Registry, Institute for Statistical and Epidemiological Cancer Research, Helsinki, Finland 


\section{Introduction}

Breast cancer is the most frequent cancer diagnosis among women globally, and the second largest cause of death among women in developed countries [1]. In the Nordic countries, the age-specific incidence of breast cancer has more than doubled during the last 65 years [2].

The most consistently reported risk factors for breast cancer are reproductive and hormonal factors including exogenous and endogenous hormones, genetic factors, lifestyle factors including alcohol consumption and obesity, exposure to ionizing radiation, and exposure to some chemicals [3-5]. However, the strength and direction of the association between these risk factors varies depending on the age at diagnosis, owing to differences in hormonal levels by menopausal status [6, 7]. Also, the association between endogenous and exogenous hormones and the risk of breast cancer varies by histology: lobular breast cancer tends to be more sensitive to endogenous and exogenous hormones than ductal breast cancer $[8,9]$. A large proportion of breast cancers cannot be explained by established risk factors [10]. Recently, several studies have reported on potential environmental and occupational exposures as potential risk factors for breast cancer, although these associations are controversial [11-13]. The strongest suggestion in relation to occupational and environmental risk factors is seen for night shift work $[14,15]$ and for exposure to ionizing radiation, as well as suggestive evidence related to endocrine-disrupting chemicals in the textile, rubber, and plastics industries [16, 17]. Some of the effects of modern working life, such as increasing sedentary work or the demand for longer education and career planning, may lead women to postpone childbirth and thus may influence their breast cancer risk. Migration studies also suggest the influence of women's environmental exposures on the risk of breast cancer [18].

There is a significant gap in the understanding of workrelated exposures and breast cancer risk. To our knowledge, most published studies are based on small populations, and only a few have taken age at diagnosis or histology into account $[19,20]$. Globally, the workforce consists of increasing numbers of women, and it is crucial to identify the risk factors for breast cancer in the work environment. In this article, we present results from a large cohort study with 45 years of followup, aiming to describe occupational variations in breast cancer incidence in the Nordic countries. This might aid the search for specific risk factors in this insufficiently explored area.

\section{Materials and methods}

\section{The NOCCA study}

The Nordic Occupational Cancer (NOCCA) Study [21] is a large population-based cohort study consisting of
14.9 million individuals $(7,454,847$ women) from all five Nordic countries (Denmark, Finland, Iceland, Norway, and Sweden) who participated in one or more population censuses in 1960, 1970, 1980/1981, or 1990. The unique personal identity codes assigned to all residents in Nordic countries were used to link data from the census to nationwide registers of cancer, death, and emigration. Personal identity codes have been systematically assigned to individuals in Finland since 1967, Sweden since 1947, Denmark since 1968, Iceland since 1953, and Norway since 1964 . The NOCCA Study was approved by relevant permission authorities according to the rules of each participating country.

The census questionnaire included questions related to individuals' economic activity, occupation, and industry. In Finland, Norway, and Sweden, occupations were coded according to national adaptations of the Nordic Occupational Classification, a Nordic version of the International Standard Classification of Occupations (ISCO). In Iceland, occupations were coded according to a national adaptation of ISCO. In Denmark, occupations were coded according to a special national nomenclature, with distinctions among self-employed persons, family workers, salaried employees, skilled workers, and unskilled workers. The basis of the coding of occupations was free-text information, provided by individuals at the time of the census, on education, occupation, industry, and employer's name and address. For the present study, the original national occupation codes were converted into a common classification with 54 occupational categories, one of which was economically inactive persons.

\section{Statistical analysis}

The individuals in the NOCCA Study were followed up from 1 January of the year following the first available census, provided that on that day the individual was 30-64 years of age. The follow-up ended at emigration, at death, or on 31 December 2003 (Norway and Denmark), 2004 (Iceland), or 2005 (Finland and Sweden), whichever came first. The information on emigration dates and death dates was obtained from the population registries. Information on breast cancer diagnoses from the Nordic cancer registries was grouped into ductal and lobular subgroups based on national topography and morphology coding systems.

The standardized incidence ratio (SIR) was used to estimate the relative risk of breast cancer incidence for each occupational category, the reference rates being the breast cancer incidence rates for the entire national female study populations. The SIR was counted as the ratio of observed and expected numbers of cases. For each country, the observed numbers of cancer cases and person years were stratified into five-year age categories and five-year calendar periods. The expected number of cases for each 
country was estimated by multiplying the incidence rates by the respective numbers of person years at risk in the NOCCA Study by country. Where there were fewer than 100 observed cases, the exact $95 \%$ confidence interval (CI) for the SIR was defined assuming a Poisson distribution of observed cancer. When the number of observed cases was $\geq 100$, the CI was calculated based on the normal approximation to Poisson distribution. The aggregate SIR for all Nordic countries was calculated as the ratio of the total number of observed cases to the total number of expected cases in the five countries. The analyses were performed using Stata 14.

We performed analysis stratified by age group at diagnosis $(<50$ and $50+$ years $)$ as a surrogate variable for pre- and postmenopausal breast cancers, given that the large majority of women in the Nordic countries below the age of 50 years are premenopausal $[22,23]$. Stratified analysis was also performed for breast cancer by histological subtype (ductal and lobular breast cancer) and calendar periods (1961-1975, 1976-1990, and 1991-2005). The ratio of the SIRs of ductal and lobular breast cancer $\left(\mathrm{SIR}_{\mathrm{DC}} / \mathrm{SIR}_{\mathrm{LC}}\right)$ and the $95 \%$ CIs were estimated using $\mathrm{R}$ statistical software [24].

\section{Results}

Altogether 373,361 cases of breast cancer were reported during the follow-up between 1961 and 2005. The SIRs for breast cancer are presented overall and based on age at diagnosis ( $<50$ years and $50+$ years), histology (ductal and lobular), and calendar periods (1961-1975, 1976-1990, and 1991-2005).

Table 1 presents the SIRs for all types of breast cancer combined, for subtypes of ductal and lobular breast cancer, and the ratio of SIRs of ductal and lobular breast cancer subtypes for different occupational categories. Overall, the highest SIR was observed for military personnel (SIR 1.58, 95\% CI 1.03-2.32), followed by dentists (SIR 1.43, 95\% CI 1.31-1.56), and physicians (SIR 1.35, 95\% CI 1.26-1.46). The lowest SIRs of breast cancer were seen among gardeners (SIR 0.76, 95\% CI 0.74-0.78), farmers (SIR 0.80, 95\% CI 0.78-0.82), woodworkers (SIR 0.75, 95\% CI 0.70-0.81), and building caretakers (SIR $0.86,95 \%$ CI $0.84-0.87$ ).

A similar pattern of elevated SIRs for both lobular and ductal carcinomas was observed among journalists, nurses, dentists, physicians, and administrators. Engine operators and woodworkers had the lowest risk of lobular breast cancer, with SIRs of 0.43 (95\% CI 0.24-0.72) and 0.53 (95\% CI 0.39-0.71), respectively. For ductal breast cancer, gardeners had the lowest risk (SIR 0.74, 95\% CI 0.71-0.77), followed by farmers and woodworkers. Significantly increased $\mathrm{SIR}_{\mathrm{DC}}$ ' $\mathrm{SIR}_{\mathrm{LC}}$ was observed among transport workers, woodworkers, building caretakers, and engine operators. The highest
$\mathrm{SIR}_{\mathrm{DC}} / \mathrm{SIR}_{\mathrm{LC}}$ ratio was observed among transport workers (SIR 1.49, 95\% CI 1.00-2.30). Decreased $\mathrm{SIR}_{\mathrm{DC}} \mathrm{SIR}_{\mathrm{LC}}$ was observed among occupational groups such as journalists, physicians, administrators, teachers, and nurses. The country-specific SIRs and 95\% CIs for different occupations are shown in Table 2. For the occupations with increased and decreased overall SIRs, country-specific SIRs across the five Nordic countries were mostly consistent.

The risk of breast cancer was significantly increased in women aged $<50$ or $50+$ years among highly educated occupational groups such as dentists, physicians, journalists, administrators, and technical workers. Welders, tobacco workers, and painters showed higher SIRs for women aged $<50$. A reduced risk of breast cancer was observed for forestry workers, welders, and fishery workers for both age groups (Fig. 1).

The SIRs of breast cancer for different occupational categories were also calculated for three 15 -year time periods (Figs. 2, 3). Journalists had the highest risk of breast cancer in 1961-1975 (SIR 1.76, 95\% CI 1.29-2.34), falling to 1.28 (95\% CI 1.15-1.42) in 1991-2005. Significantly, an increased risk of breast cancer was observed for laboratory workers only in the latest period (1991-2005), while there was no excess in the periods before that (1976-1990 and 1961-1975). Farmers, forestry workers, drivers, and gardeners had low risks during all time periods.

\section{Discussion}

The present study explored the association between breast cancer and occupation among women in the Nordic countries. The occupational groups with an overall increased risk of breast cancer were healthcare professionals, religious workers, artistic workers, journalists, women in administrative and clerical work, sales agents, transport workers, print workers, military personnel, postal workers, hairdressers, and public safety workers. The SIR for lobular cancer was comparatively higher than for ductal cancer in most of the occupations that showed an increased risk, while some occupational groups such as domestic assistants, building caretakers, chimney sweeps, and hairdressers had a significant elevation for lobular cancer only. Most of the $\mathrm{SIR}_{\mathrm{DC}}$ ' SIR $_{L C}$ was insignificant, showing that the risk of breast cancer in those occupations did not differ strongly by histology. Increased $\mathrm{SIR}_{\mathrm{DC}} / \mathrm{SIR}_{\mathrm{LC}}$ was observed among transport workers, woodworkers, building caretakers, and engine operators, while a decreased $\mathrm{SIR}_{\mathrm{DC}} / \mathrm{SIR}_{\mathrm{LC}}$ was observed among groups such as journalists, physicians, administrators, teachers, and nurses.

A wide range of white-collar jobs in our study-including administrative work, clerical work, teaching, health work, and technical work-were associated with an 


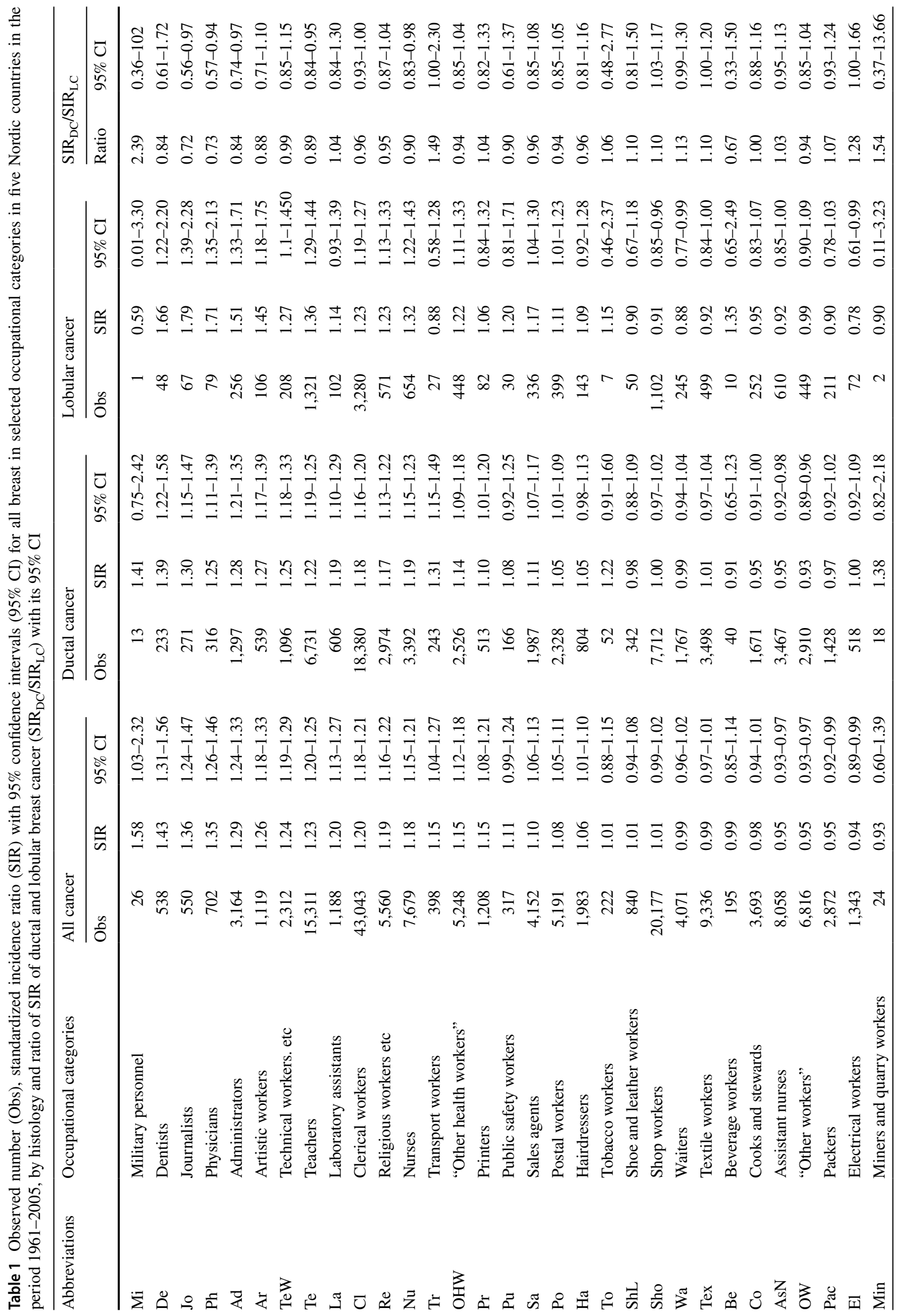




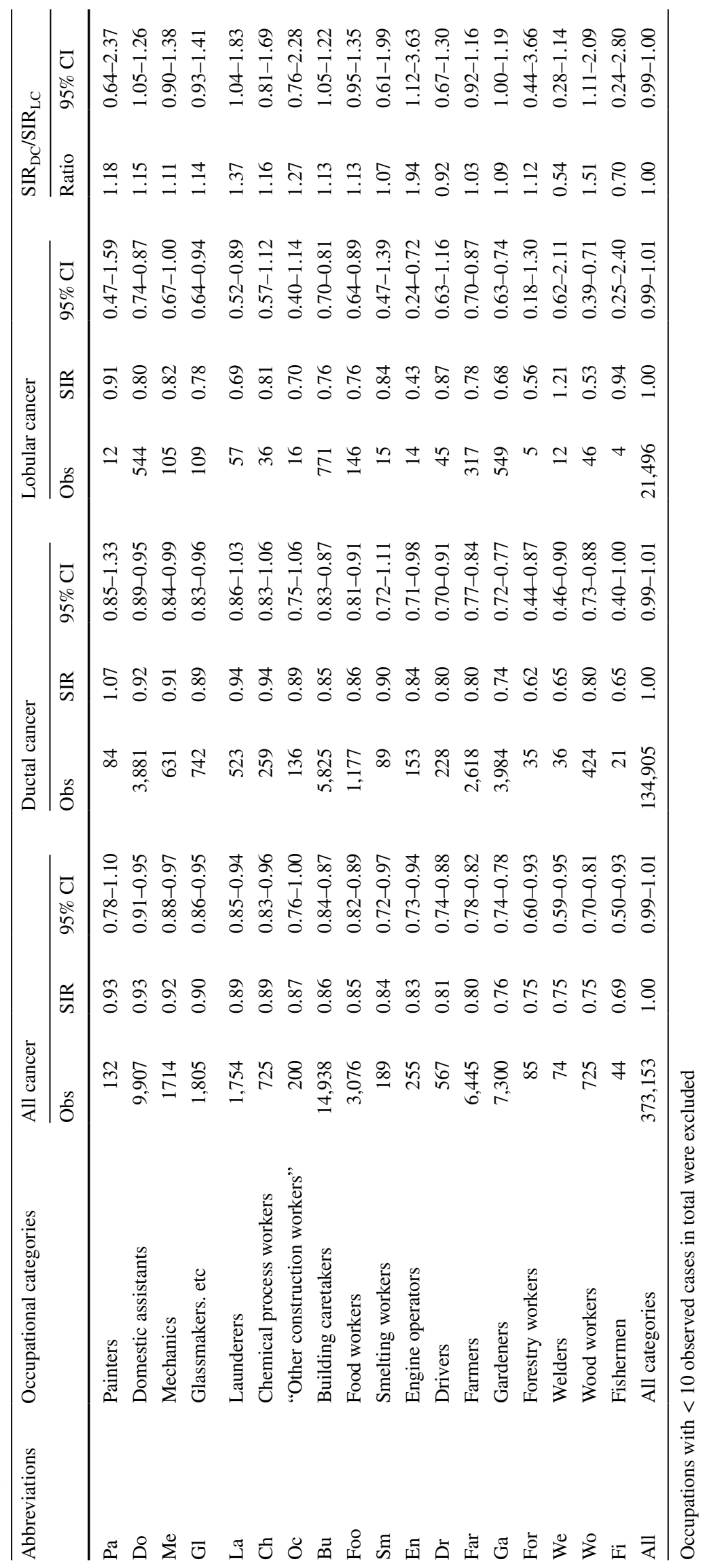




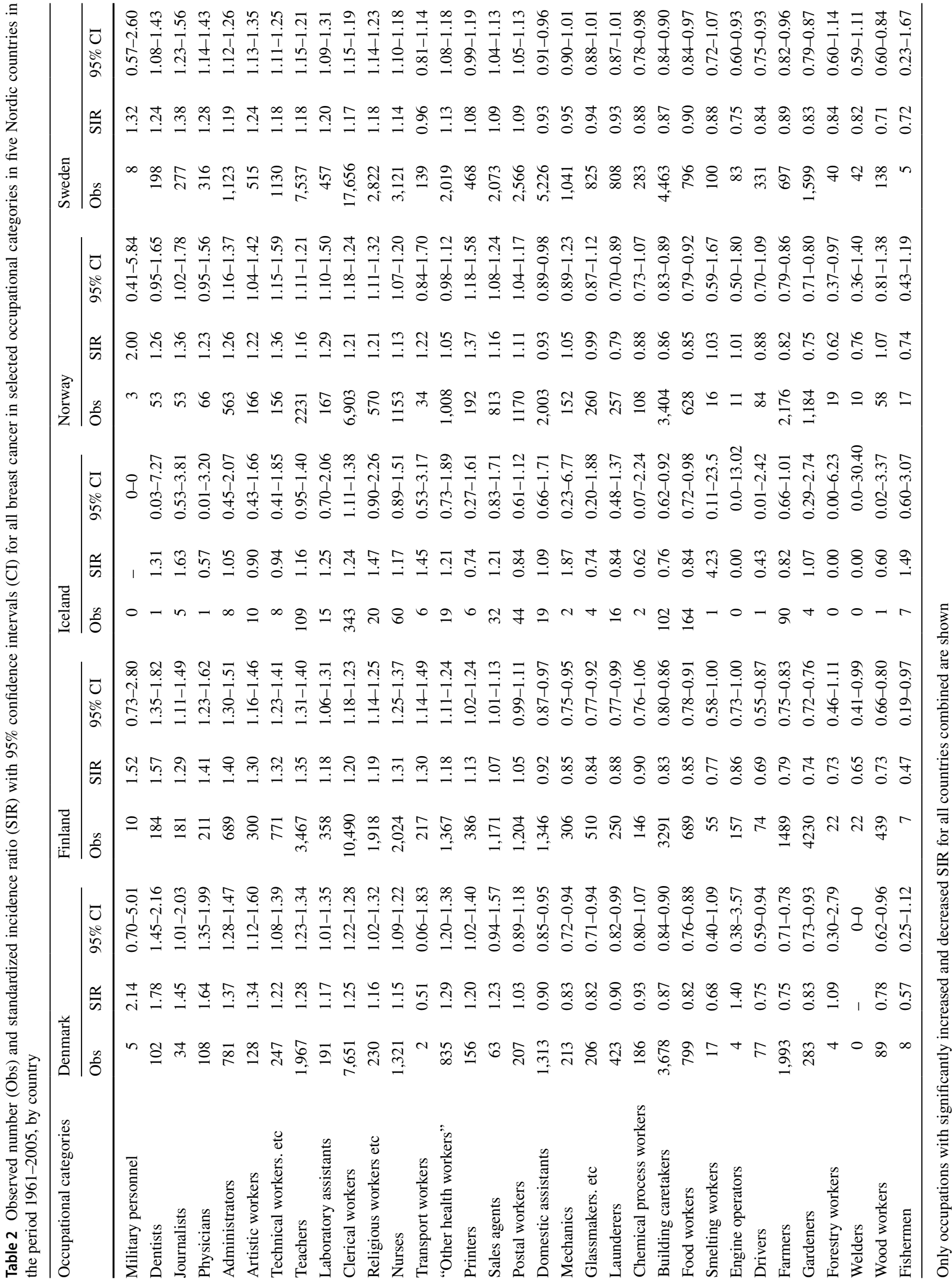




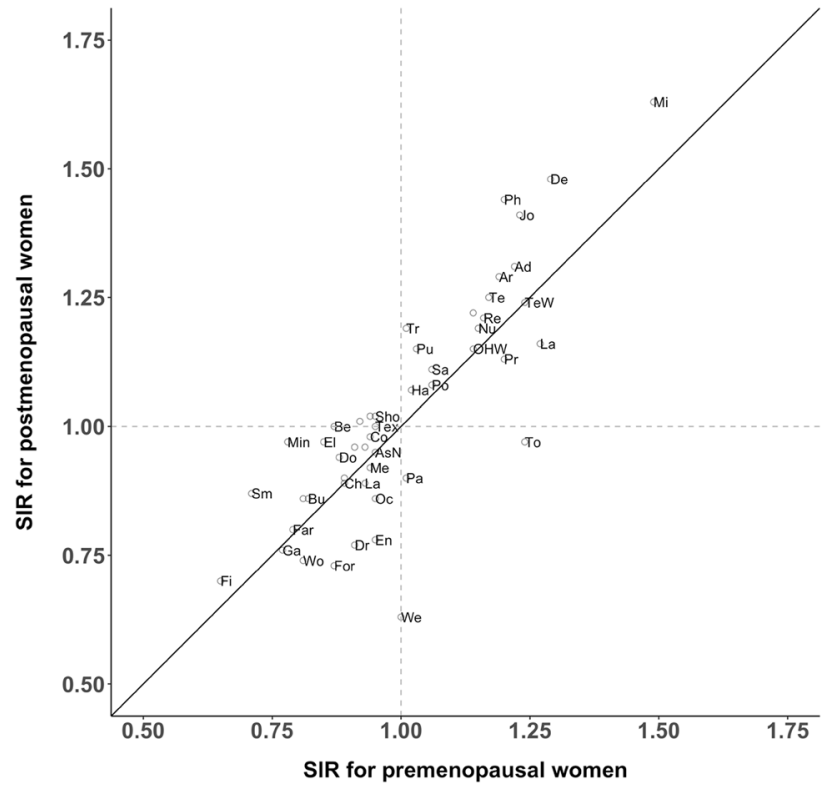

Fig. 1 Correlation of premenopausal and postmenopausal breast cancer SIRs for different occupational categories. Occupations with $<10$ cases in total were excluded. Abbreviations for the occupations are explained in Table 1

increased risk of breast cancer. Our results are consistent with other findings from Nordic [25] and other countries $[20,26,27]$. It is difficult to interpret the association of these occupations with an increased risk of breast cancer, since we do not have information on the specific exposures related to each occupation. However, one possible link for the high SIRs observed in these occupations, which require higher levels of education, might be such women's postponement of first childbirth and their birthing of fewer children in their lifetime. Early age at first childbirth and an increased number of children are established protective factors in relation to breast cancer [28-30]. These factors could not be adjusted for in our study; however, one large Swedish cohort study showed that, even after adjustment for an extensive set of reproductive factors including breastfeeding, hormonal replacement therapy, and lifestyle factors, the risk for white-collar workers was still high [25]. This and other studies suggest that estrogen-related pathways explain only a small proportion of the elevated breast cancer risk among professional women, and social stress pathways might potentially be more important $[31,32]$. Chronic stress at work results in systematically elevated levels of cortisol [31]. Normal levels of cortisol contribute to the lobuloalveolar development of mammary glands, and also aid the process of lactation [32]. However, a prolonged elevated level of cortisol production is likely to expose the mammary cells to an adverse environment, as well as contributing to breast tumorigenesis by altering the generation or activity of estrogen [33, 34].

A recent study [32] suggested that working women might have experienced more interpersonal stress in the 1970s compared with recent years due to societal norms. We also observed differences in risk among white-collar occupations in different study calendar periods, with lower risks in the most recent calendar periods compared with earlier years. It is conceivable that white-collar workers might be subjected
Fig. 2 Breast cancer standardized incidence ratio (SIR), by occupational categories with increased overall risk and time period (1961 through 2005) among women in five Nordic countries. $p$ value of linear trend for each occupational category is shown

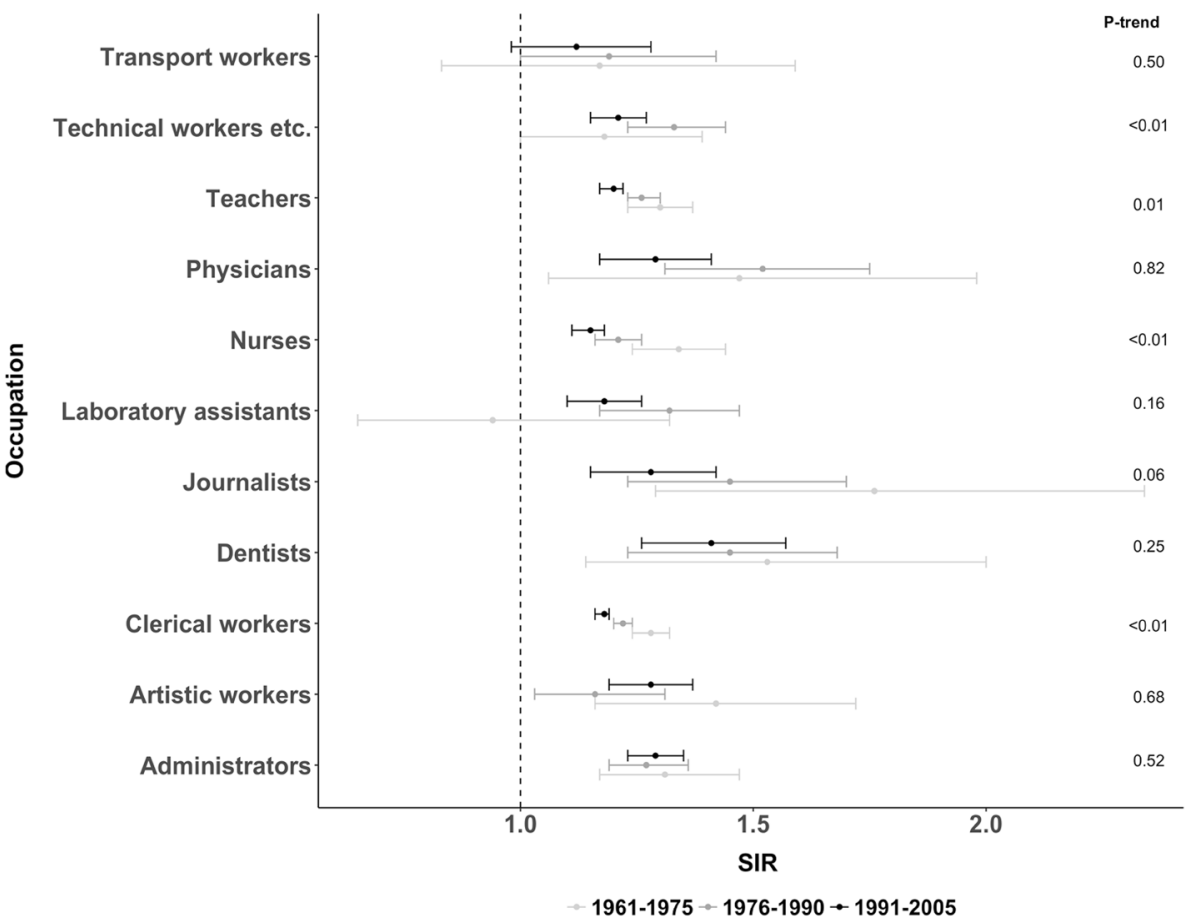




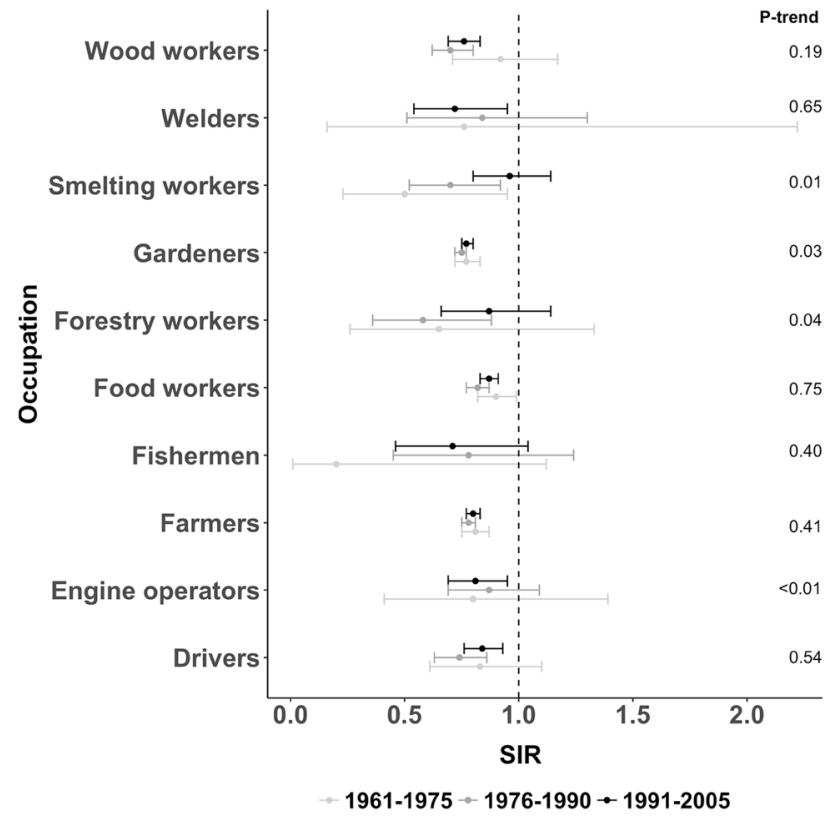

Fig. 3 Breast cancer standardized incidence ratio (SIR), by occupational categories with decreased overall risk and time period (1961 through 2005) among women in 5 Nordic countries. $p$ value of linear trend for each occupational category is shown

to a higher level of stress due to higher work demands, and might thus be at higher risk of breast cancer. However, the few studies conducted on the association between workrelated stress and breast cancer have been limited to the nursing profession only, and have shown no indication of any such risk association $[35,36]$. We also noted that the SIR for lobular cancer compared with ductal breast cancer $\left(\mathrm{SIR}_{\mathrm{DC}} / \mathrm{SIR}_{\mathrm{LC}}\right)$ was significantly higher among many whitecollar workers, which is conceivably because lobular cancer is hormone sensitive; a consistently stronger association between age at first childbirth and exogenous hormones has been shown for lobular breast cancer compared with ductal breast cancer [37-41].

Furthermore, the increase in breast cancer risk among white-collar workers could be related to such workers' higher educational status and income. Studies show that more educated women and those with higher incomes are more likely to participate in breast cancer screening [42-45]. In the Nordic countries, the incidence of breast cancer increased markedly after the introduction of mammographic screening, and it remains elevated among women who continue to be screened compared with women who do not get screening [46, 47]. Compared with the early 1980s, there has been a steep increase in breast cancer incidence in recent years, with a peak at the age of 65 years. In addition, the incidence of breast cancer has increased in recent years among premenopausal women over the age of 40 , which might indicate self-initiated opportunistic mammographic screening in these age groups [2].

The International Agency for Research on Cancer (IARC) has classified shift work that involves circadian disruption as probably carcinogenic to humans, based on sufficient evidence in experimental animals but limited evidence in humans [13]. Exposure to light during night-time leads to the suppression of the production of the pineal hormone melatonin, thus influencing a rise in estrogen production and leading to the possibility of breast cancer development [48]. A study among Finnish women reported the decreased risk of breast cancer by degree of visual impairment which suggest towards the positive association between visible light at night and breast cancer risk via alteration in melatonin hormone [49]. Some recent systematic reviews and metaanalyses [50, 51] have suggested that shift work increases the risk of breast cancer by $48 \%$; however, one meta-analysis has indicated insufficient evidence of, or minimal or no effect on, the risk of breast cancer [52]. A cohort study among Swedish twins suggested that night work was associated with breast cancer risk, but only after long-term exposure [53]. Similarly, a study among Finnish cabin attendants did not show any statistically significant association with sleep rhythm disruption [54]. Studies on night shift work among nurses have shown a positive association with breast cancer $[55,56]$. An increased risk was also observed for military women in previous studies $[57,58]$. Nurses and military workers in our study showed an increased risk of breast cancer in pre- and postmenopausal age groups and during each time period, but these findings are inconclusive in the absence of information regarding the frequency and duration of night shifts worked or adjustment for other possible risk factors.

In our study, other health professionals apart from nurses also showed an elevated risk of breast cancer, including dentists, laboratory assistants, and physicians. Health workers might be exposed to ionizing radiation, which the IARC states is carcinogenic to the human breast, with sufficient evidence and shown in other studies [59-61]. In a Finnish study that assessed the association between cumulative radiation exposure and cancer incidence among physicians by systematically monitoring radiation exposure, there was a significantly increased risk of breast cancer among exposed physicians compared with the non-exposed group [62]. Laboratory workers are likely to be exposed to carcinogenic chemicals and organic solvents that have been shown to be associated with an increased risk of breast cancer [63, 64]. In our study, the increased risk among laboratory workers in recent years might reflect advances in medical laboratory technologies and the increased exposure of these workers to ionizing radiation and other potentially carcinogenic chemical compounds. 
While ionizing radiation has an established association with breast cancer, the IARC has classified exposure to non-ionizing radiation-specifically, exposure to electromagnetic fields (EMF) — as having possible but inadequate evidence for a breast cancer risk. Some studies have identified an increased risk of breast cancer associated with electrical work $[65,66]$ or electromagnetic radiation [67]; however, we did not observe any such association among electrical workers in any time period for the Nordic countries.

The IARC has stated that there is inadequate evidence for the carcinogenicity of printing inks in humans or of the possibility that printing processes might be carcinogenic to human beings. In our study, printing and publishing workers had an increased risk of breast cancer in both age groups ( $<50$ years and $\geq 50$ years). A study by Lynge et al. [68] based on Danish data, which overlaps with the NOCCA data, suggested a significantly higher SIR of breast cancer (SIR 1.35, 95\% CI 1.08-1.66) among women working in the printing and publishing industry. In agreement with our Nordic study, a case-control study of breast cancer among premenopausal women based on the British Columbia cancer registry showed an elevated risk of breast cancer among younger women working in printing [65].

Some previous studies have suggested an elevated risk of breast cancer among agricultural populations [65, 69] that might be related to exposure to pesticides during farming; for example, not wearing protective equipment during chemical use increases the risk of breast cancer. Chemical compounds such as organochlorines and dichlorodiphenyltrichloroethane, which are frequently used as pest and insect control measures, are reportedly carcinogenic to the human breast [70,71]. Studies have recently suggested that these estrogenic environmental compounds, often referred to as 'xenoestrogens,' are formed by the interaction of many chemicals in the environment, and are stored in breast tissue and interfere with endogenous estrogen. Xenoestrogen has been linked to the neoplastic transformation of the human breast $[72,73]$. However, in the current study's long-term follow-up of the Nordic population, we did not find any elevated risk of breast cancer among farmers or gardeners, which is similar to findings from some other recent studies $[20,74]$. On the contrary, women in farming had a deficit risk of breast cancer. With reference to a Finnish survey among working-age cancer cases, there is increased parity among agricultural occupations compared with academic occupations, which might possibly be one explanation for the protective effect observed among females in these occupations in the Nordic population [75].

Women in sedentary occupations have been reported to be at increased risk of breast cancer compared with women in non-sedentary occupations [76-78]. In this study, we could not precisely categorize or define sedentary occupations.
However, the protective effect on breast cancer among farmers, gardeners, woodworkers, and forestry workers might tend to suggest that an active lifestyle is associated with a decreased risk [79]. On the other hand, sedentary work environments, such as those of administrative workers, had an increased risk.

The strength of this study is its large study population and its long-term follow-up of individuals. Further, the high quality and completeness of the Nordic countries' nationwide population registers, and the record linkage system via unique personal identity codes, ensures accurate follow-up measurements and accurate assessments of breast cancer cases [80].

Our study also has limitations. There were some heterogeneous occupational categories, and it was not always possible to evaluate the actual occupational risk associated with specific exposures within such categories. Information on each individual's occupation was obtained only at the first census in which the individual participated, and might possibly have varied across the individual's lifetime. Another major limitation was that there was a lack of data regarding potential confounding by well-known risk factors for breast cancer, and hence we could not adjust for these factors.

In conclusion, this study suggests that breast cancer risk is heterogeneously distributed among different occupations in the Nordic population. The study also suggests that breast cancer risks based on occupation differ markedly by histology in some occupational categories. It was not within the scope of our study to separate the roles of strictly occupation-related exposures from the effects of individual and lifestyle factors, but evidently there would be a need for further studies to precisely explain the variations in breast cancer risk by occupation.

\section{References}

1. Ferlay J, Soerjomataram I, Ervik M, Dikshit R, Eser S, Mathers C, Rebelo M, Parkin DM, Forman D, Bray F (2013) Cancer incidence and mortality worldwide: IARC cancer base no. 11. http:// globocan.iarc.fr. Accessed 6 March 2017

2. Engholm G, Ferlay J, Christensen N, Hansen HL, HertzumLarsen R, Johannesen TB, Kejs AMT, Khan S, Ólafsdóttir E, Petersen T, Schmidt LKH, Virtanen A, Storm HH (2017) Cancer incidence, mortality, prevalence and survival in the Nordic countries, version 8.0. http://www.ancr.nu. Accessed 27 Dec 2017

3. Ma H, Bernstein L, Pike MC, Ursin G (2006) Reproductive factors and breast cancer risk according to joint estrogen and progesterone receptor status: a meta-analysis of epidemiological studies. Breast Cancer Res 8(4):R43. https://doi.org/10.1186/bcr1525

4. Key TJ, Verkasalo PK, Banks E (2001) Epidemiology of breast cancer. Lancet Oncol 2(3):133-140 
5. Weiderpass E, Meo M, Vainio H (2011) Risk factors for breast cancer, including occupational exposures. Saf Health Work 2(1):1-8. https://doi.org/10.5491/SHAW.2011.2.1.1

6. Janerich DT, Hoff MB (1982) Evidence for a crossover in breast cancer risk factors. Am J Epidemiol 116:737-742

7. Tryggvadottir L, Tulinius H, Eyfjord JE, Sigurvinsson T (2002) Breast cancer risk factors and age at diagnosis: an Icelandic cohort study. Int J Cancer 98(4):604-608

8. Nickels S, Truong T, Hein R, Stevens K, Buck K, Behrens S et al (2013) Evidence of gene-environment interactions between common breast cancer susceptibility loci and established environmental risk factors. PLOS Genet 9(3):e1003284

9. Li CI, Weiss NS, Stanford JL, Daling JR (2000) Hormone replacement therapy in relation to risk of lobular and ductal breast carcinoma in middle-aged women. Cancer 88(11):2570-2577

10. Sasco AJ (2001) Epidemiology of breast cancer:. an environmental disease? APMIS 109(5):321-332

11. Lichtenstein P, Holm NV, Verkasalo PK, Iliadou A, Kaprio J, Koskenvuo M et al (2000) Environmental and heritable factors in the causation of cancer: analyses of cohorts of twins from Sweden, Denmark, and Finland. N Engl J Med 343(2):78-85

12. Slack R, Young C, Rushton L, British Occupational Cancer Burden Study Group (2012) Occupational cancer in Britain: female cancers-breast, cervix and ovary. Br J Cancer 107(Suppl. 1):S27-S32

13. IARC Working Group on the Evaluation of Carcinogenic Risks to Humans (2010) Painting, firefighting, and shiftwork. IARC Monogr Eval Carcinog Risks Hum 98:9-764

14. Schernhammer ES, Kroenke CH, Laden F, Hankinson SE (2006) Night work and risk of breast cancer. Epidemiology 17(1):108-111

15. Stevens RG (2009) Light-at-night, circadian disruption and breast cancer: assessment of existing evidence. Int J Epidemiol 38(4):963-970

16. Feychting M, Forssen U (2006) Electromagnetic fields and female breast cancer. Cancer Causes Control 17(4):553-558

17. Broeks A, Braaf LM, Wessels LF, van de Vijver M, De Bruin ML, Stovall M et al (2010) Radiation-associated breast tumors display a distinct gene expression profile. Int J Radiat Oncol Biol Phys 76(2):540-547

18. Ziegler RG, Hoover RN, Pike MC, Hildesheim A, Nomura AM, West DW et al (1993) Migration patterns and breast cancer risk in Asian-American women. J Natl Cancer Inst 85:1819-1827

19. Peplonska B, Stewart P, Szeszenia-Dąbrowska N, Lissowska J, Brinton LA, Gromiec JP et al (2010) Occupational exposure to organic solvents and breast cancer in women. Occup Environ Med 67(11):722-729

20. Ji BT, Blair A, Shu XO, Chow WH, Hauptmann M, Dosemeci $M$ et al (2008) Occupation and breast cancer risk among Shanghai women in a population-based cohort study. Am J Ind Med 51(2):100-110

21. Pukkala E, Martinsen JI, Lynge E, Gunnarsdottir HK, Sparén P, Tryggvadottir L et al (2009) Occupation and cancer-followup of 15 million people in five nordic countries. Acta Oncol 48(5):646-790

22. Pakarinen M, Raitanen J, Kaaja R, Luoto R (2010) Secular trend in the menopausal age in Finland 1997-2007 and correlation with socioeconomic, reproductive and lifestyle factors. Maturitas 66(4):417-422

23. Brandt J, Garne JP, Tengrup I, Manjer J (2015) Age at diagnosis in relation to survival following breast cancer: a cohort study. World J Surg Oncol 13:33. https://doi.org/10.1186/s1295 7-014-0429-x

24. Altman DG, Machin D, Bryant TN, Gardner MJ (2000) Statistics with confidence: confidence intervals and statistical guidelines, 2nd edn. BMJ Books, London
25. Kullberg C, Selander J, Albin M, Borgquist S, Manjer J, Gustavsson P (2017) Female white-collar workers remain at higher risk of breast cancer after adjustments for individual risk factors related to reproduction and lifestyle. Occup Environ Med 74(9):652-658

26. Goldberg MS, Labreche F (1996) Occupational risk factors for female breast cancer: a review. Occup Environ Med 53(3): $145-156$

27. Gardner KM, Ou SX, Jin F, Dai Q, Ruan Z, Thompson SJ et al (2002) Occupations and breast cancer risk among Chinese women in urban Shanghai. Am J Ind Med 42(4):296-308

28. Pathak DR, Speizer FE, Willett WC, Rosner B, Lipnick RJ (1986) Parity and breast cancer risk: possible effect on age at diagnosis. Int J Cancer 37(1):21-25

29. Hsieh C, Pavia M, Lambe M, Lan SJ, Colditz GA, Ekbom A et al (1994) Dual effect of parity on breast cancer risk. Eur J Cancer 30A(7):969-973

30. Larsen SB, Olsen A, Lynch J, Christensen J, Overvad K, Tjønneland A et al (2011) Socioeconomic position and lifestyle in relation to breast cancer incidence among postmenopausal women: a prospective cohort study, Denmark, 1993-2006. Cancer Epidemiol 35(5):438-441

31. Pudrovska T (2013) Job authority and breast cancer. Soc Forces 92(1):1-24. https://doi.org/10.1093/sf/sot082

32. Maina G, Bovenzi M, Palmas A, Larese Filon F (2009) Associations between two job stress models and measures of salivary cortisol. Int Arch Occup Environ Health 82(9):1141-1150

33. Reichardt HM, Horsch K, Grone HJ, Kolbus A, Beug H, Hynes $\mathrm{N}$ et al (2001) Mammary gland development and lactation are controlled by different glucocorticoid receptor activities. Eur J Endocrinol 145(4):519-527

34. Russo J, Hasan Lareef M, Balogh G, Guo S, Russo IH (2003) Estrogen and its metabolites are carcinogenic agents in human breast epithelial cells. J Steroid Biochem Mol Biol 87(1):1-25

35. Schernhammer ES, Hankinson SE, Rosner B, Kroenke C, Willett WC, Colditz GA et al (2004) Job stress and breast cancer risk: the Nurses' Health Study. Am J Epidemiol 160(11):1079-1086

36. Nielsen NR, Stahlberg C, Strandberg-Larsen K, Kristensen TS, Zhang ZF, Hundrup YA et al (2008) Are work-related stressors associated with diagnosis of more advanced stages of incident breast cancers? Cancer Causes Control 19(3):297-303

37. Granström C, Sundquist J, Hemminki K (2008) Population attributable risks for breast cancer in Swedish women by morphological type. Breast Cancer Res Treat 111(3):559-568

38. Li CI, Daling JR, Malone KE, Bernstein L, Marchbanks PA, Liff JM et al (2006) Relationship between established breast cancer risk factors and risk of seven different histologic types of invasive breast cancer. Cancer Epidemiol Biomarkers Prev 15(5):946-954

39. Kotsopoulos J, Chen WY, Gates MA, Tworoger SS, Hankinson SE, Rosner BA (2010) Risk factors for ductal and lobular breast cancer: results from the Nurses' Health Study. Breast Cancer Res 12(6):R106

40. Newcomer LM, Newcomb PA, Potter JD, Yasui Y, TrenthamDietz A, Storer BE et al (2003) Postmenopausal hormone therapy and risk of breast cancer by histologic type (United States). Cancer Causes Control 14(3):225-233

41. Li CI, Daling JR, Haugen KL, Tang MT, Porter PL, Malone KE (2014) Use of menopausal hormone therapy and risk of ductal and lobular breast cancer among women 55-74 years of age. Breast Cancer Res Treat 145(2):481-489

42. Jensen LF, Pedersen AF, Andersen B, Vedsted P (2012) Identifying specific non-attending groups in breast cancer screening: population-based registry study of participation and socio-demography. BMC Cancer. https://doi. org/10.1186/1471-2407-12-518 
43. Finkelstein MM (2002) Preventive screening: what factors influence testing? Can Fam Physician 48:1494-1501

44. Akinyemiju T, Ogunsina K, Sakhuja S, Ogbhodo V, Braithwaite D (2016) Life-course socioeconomic status and breast and cervical cancer screening: analysis of the WHO's study on global ageing and adult health (SAGE). BMJ Open. https://doi. org/10.1136/bmjopen-2016-012753

45. Damiani G, Federico B, Basso D, Ronconi A, Bianchi CB, Anzellotti GM et al (2012) Socioeconomic disparities in the uptake of breast and cervical cancer screening in Italy: a cross sectional study. BMC Public Health https://doi. org/10.1186/1471-2458-12-99

46. Hofvind S, Sakshaug S, Ursin G, Graff-Iversen S (2012) Breast cancer incidence trends in Norway: explained by hormone therapy or mammographic screening? Int J Cancer 130(12):2930-2938

47. Møller B, Weedon- Fekjær H, Hakulinen T, Tryggvadóttir L, Storm HH, Talbäck M et al (2005) The influence of mammographic screening on national trends in breast cancer incidence. Eur J Cancer Prev 14(2):117-128

48. Stevens RG, Davis S (1996) The melatonin hypothesis: electric power and breast cancer. Environ Health Perspect 104(Suppl. 1): $135-140$

49. Pukkala E, Ojamo M, Rudanko SL, Stevens RG, Verkasalo PK (2006) Does incidence of breast cancer and prostate cancer decrease with increasing degree of visual impairment. Cancer Causes Control 17(4):573-576

50. Hansen J (2017) Night shift work and risk of breast cancer. Curr Environ Health Rep 4(3):325-339

51. Yuan X, Zhu C, Wang M, Mo F, Du W, Ma X (2018) Night shift work increases the risks of multiple primary cancers in women: a systematic review and meta-analysis of 61 articles. Cancer Epidemiol Biomark Prev 27(1):25-40

52. Ijaz S, Verbeek J, Seidler A, Lindbohm ML, Ojajarvi A, Orsini N et al (2013) Night-shift work and breast cancer: a systematic review and meta-analysis. Scand J Work Environ Health 39(5):431-447

53. A kerstedt T, Knutsson A, Narusyte J, Svedberg P, Kecklund G, Alexanderson K (2015) Night work and breast cancer in women: a Swedish cohort study. BMJ Open. https://doi.org/10.1136/ bmjopen-2015-008127

54. Kojo K, Pukkala E, Auvinen A (2005) Breast cancer risk among Finnish cabin attendants: a nested case-control study. Occup Environ Med 62(7):488-493

55. Lie JA, Kjuus H, Zienolddiny S, Haugen A, Stevens RG, Kjaerheim K (2011) Night work and breast cancer risk among Norwegian nurses: assessment by different exposure metrics. Am J Epidemiol 173(11):1272-1279

56. Hansen J, Stevens RG (2012) Case-control study of shift-work and breast cancer risk in Danish nurses: impact of shift systems. Eur J Cancer 48(11):1722-1729

57. Rennix CP, Quinn MM, Amoroso PJ, Eisen EA, Wegman DH (2005) Risk of breast cancer among enlisted Army women occupationally exposed to volatile organic compounds. Am J Ind Med 48(3):157-167

58. Hansen J, Lassen CF (2012) Nested case-control study of night shift work and breast cancer risk among women in the Danish military. Occup Environ Med 69(8):551-556. https://doi. org/10.1136/oemed-2011-100240

59. IARC Working Group on the Evaluation of Carcinogenic Risks to Humans (2000) Ionizing radiation, part 1: X- and gamma radiation, and neutrons. IARC Monogr Eval Carcinog Risks Hum 75:1-459

60. Chou LB, Chandran S, Harris AH, Tung J, Butler LM (2012) Increased breast cancer prevalence among female orthopedic surgeons. J Womens Health (Larchmt) 21(6):683-689
61. Weiderpass E, Pukkala E, Kauppinen T, Mutanen P, Paakkulainen H, Vasama-Neuvonen K et al (1999) Breast cancer and occupational exposures in women in Finland. Am J Ind Med 36(1):48-53

62. Jartti P, Pukkala E, Uitti J, Auvinen A (2006) Cancer incidence among physicians occupationally exposed to ionizing radiation in Finland. Scand J Work Environ Health 32(5):368-373

63. Gustavsson P, Andersson T, Gustavsson A, Reuterwall C (2017) Cancer incidence in female laboratory employees: extended follow-up of a Swedish cohort study. Occup Environ Med 74(11):823-826

64. Hansen J (1999) Breast cancer risk among relatively young women employed in solvent-using industries. Am J Ind Med 36(1):43-47

65. Band PR, Le ND, Fang R, Deschamps M, Gallagher RP, Yang P (2000) Identification of occupational cancer risks in British Columbia: a population-based case-control study of 995 incident breast cancer cases by menopausal status, controlling for confounding factors. J Occup Environ Med 42(3):284-310

66. McElroy JA, Egan KM, Titus-Ernstoff L, Anderson HA, Trentham-Dietz A, Hampton JM et al (2007) Occupational exposure to electromagnetic field and breast cancer risk in a large, population-based, case-control study in the United States. J Occup Environ Med 49(3):266-274

67. Forssen UM, Rutqvist LE, Ahlbom A, Feychting M (2005) Occupational magnetic fields and female breast cancer: a casecontrol study using Swedish population registers and new exposure data. Am J Epidemiol 161(3):250-259

68. Lynge E, Rix BA, Villadsen E, Andersen I, Hink M, Olsen E et al (1995) Cancer in printing workers in Denmark. Occup Environ Med 52(11):738-744

69. Brophy JT, Keith MM, Watterson A, Park R, Gilbertson M, Maticka-Tyndale E et al (2012) Breast cancer risk in relation to occupations with exposure to carcinogens and endocrine disruptors: a Canadian case-control study. Environ Health. https://doi. org/10.1186/1476-069X-11-87

70. Snedeker SM (2001) Pesticides and breast cancer risk: a review of DDT, DDE, and dieldrfSIRin. Environ Health Perspect 109(Suppl. 1):35-47

71. Adami HO, Lipworth L, Titus-Ernstoff L, Hsieh CC, Hanberg A, Ahlborg U et al (1995) Organochlorine compounds and estrogen-related cancers in women. Cancer Causes Control 6(6):551-566

72. Fernandez SV, Russo J (2010) Estrogen and xenoestrogens in breast cancer. Toxicol Pathol 38(1):110-122

73. Macon MB, Fenton SE (2013) Endocrine disruptors and the breast: early life effects and later life disease. J Mammary Gland Biol Neoplasia 18(1):43-61

74. Lemarchand C, Tual S, Boulanger M, Levêque-Morlais N, Perrier S, Clin B et al (2016) O14-4: breast cancer risk among postmenopausal women in the agriculture and cancer cohort. Occup Environ Med 73(Suppl 1):A27

75. Pukkala E (1995) Cancer risk by social class and occupation: a survey of 109,000 cancer cases among Finns of working age. In: Wahrendorf $\mathbf{J}$ (ed) Contributions to epidemiology and biostatistics, vol 7. Karger, Basel

76. Johnsson A, Broberg P, Johnsson A, Tornberg AB, Olsson $\mathrm{H}$ (2017) Occupational sedentariness and breast cancer risk. Acta Oncol 56(1):75-80

77. Luoto R, Latikka P, Pukkala E, Hakulinen T, Vihko V (2000) The effect of physical activity on breast cancer risk: a cohort study of 30,548 women. Eur J Epidemiol 16:973-980

78. Rintala P, Pukkala E, Läärä E, Vihko V (2003) Physical activity and breast cancer risk among female physical education and language teachers: a 34-year follow-up. Int J Cancer 107:268-270 
79. Kauppinen T, Heikkilä P, Plato N, Woldbaek T, Lenvik K, Hansen J et al (2009) Construction of job-exposure matrices for the Nordic Occupational Cancer Study (NOCCA). Acta Oncol 48(5):791-800

80. Pukkala E, Engholm G, Højsgaard Schmidt LK, Storm H, Khan S, Lambe M, Pettersson D, Ólafsdóttir E, Tryggvadóttir L, Hakanen
T, Malila N, Virtanen A, Johannesen TB, Larønningen S, Ursin G (2018) Similarities and differences of the Nordic cancer registries: an overview of their procedures and data comparability. Acta Oncol 57:440-455 